\title{
Promoter Hypermethylation in White Blood Cell DNA and Breast Cancer Risk
}

\author{
Yoon Hee Cho ${ }^{1,8}, \bowtie$, Lauren E. McCullough², Marilie D. Gammon², Hui-Chen Wu1, Yu-Jing Zhang', Qiao \\ Wang ${ }^{1}$, Xinran $\mathrm{Xu}^{3}$, Susan L. Teitelbaum ${ }^{3}$, Alfred I. Neugut ${ }^{4,5}$, Jia Chen ${ }^{3,6,7}$, Regina M. Santella ${ }^{1}$ \\ 1. Department of Environmental Health Sciences, Columbia University, 630 West $168^{\text {th }}$ St, New York, NY 10032, USA \\ 2. Department of Epidemiology, University of North Carolina at Chapel Hill, 135 Dauer Drive, Chapel Hill, NC 27599, USA \\ 3. Department of Preventive Medicine, Mount Sinai School of Medicine, 1468 Madison Ave, New York, NY 10029, USA \\ 4. Department of Epidemiology, Columbia University, 722 West $168^{\text {th }}$ St, New York, NY 10032, USA \\ 5. Department of Medicine, Columbia University, 161 Fort Washington Ave at W $165^{\text {th }}$ St, New York, NY 10032, USA \\ 6. Department of Pediatrics, Mount Sinai School of Medicine, One Gustave L. Levy Place Box 1198, New York, NY 10029, USA \\ 7. Department of Oncological Science, Mount Sinai School of Medicine, One Gustave L. Levy Place Box 1130, New York, NY 10029, USA \\ 8. Current address: Departments of Biomedical and Pharmaceutical Sciences, University of Montana, 32 Campus Drive, Missoula, MT \\ 59812, USA
}

\begin{abstract}
$\triangle$ Corresponding author: Yoon Hee Cho, Ph.D., Department of Biomedical and Pharmaceutical Sciences, College of Health Professions and Biomedical Sciences, The University of Montana. 32 Campus Drive, Skaggs 283, Missoula, MT 59812. Phone: 1-406-243-4529; Fax: 1-403-243-2807; E-mail: yoonhee.cho@umontana.edu
\end{abstract}

C 2015 Ivyspring International Publisher. Reproduction is permitted for personal, noncommercial use, provided that the article is in whole, unmodified, and properly cited. See http://ivyspring.com/terms for terms and conditions.

Received: 2015.03.19; Accepted: 2015.05.07; Published: 2015.07.15

\begin{abstract}
The role of gene-specific methylation in white blood cells $(\mathrm{WBC})$ as a marker of breast cancer risk is currently unclear. We determined whether promoter hypermethylation in blood DNA of candidate tumor suppressor genes frequently methylated in breast tumors can be used as a surrogate biomarker for breast cancer risk. Promoter methylation of $B R C A I, C D H I$ and $R A R \beta$ was analyzed in WBC DNA from a population-based sample of 1,021 breast cancer patients and 1,036 controls by the MethyLight assay. Gene-specific promoter methylation in the DNA of 569 tumor tissue samples was also analyzed to determine the correlation of methylation levels with blood from the same individual. Hypermethylation of BRCAI (OR: 1.31; 95\% Cl: 0.98-1.75) in WBC was associated with an increased risk of breast cancer when positive methylation was defined as $\geq 0.1 \%$ methylated. There was lack of concordance between tumor tissue and paired WBC DNA methylation. These results provide limited support that hypermethylation of $B R C A l$ in WBC DNA may be useful for determination of breast cancer risk. Additional studies with larger numbers of genes are needed to fully understand the relationship between WBC methylation and breast cancer risk.
\end{abstract}

Key words: Breast cancer, Promoter methylation, BRCA1, white blood cell DNA

\section{Introduction}

Aberrant hypermethylation in promoter regions of genes is now recognized as an important and early event in carcinogenesis [1]. To date, CpG island hypermethylation has been shown to inactivate more than 70 genes in breast tumor tissues [2]. Among these genes, breast cancer-related tumor suppressor genes, $B R C A 1, C D H 1$ and $R A R \beta$ are frequently hypermethylated in breast cancer [3-5]. Numerous studies have confirmed the hypothesis that aberrant methylation of specific genes contributes to the malignant phenotype of breast cancer [6-9].

It is increasingly recognized that tumor DNA can be found in the bloodstream of cancer patients and that this DNA frequently contains the same genetic and epigenetic alterations as DNA isolated from an individual's tumor [10-12]. This suggests that detec- 
tion of tumor DNA in blood may serve as an early and more accessible marker for diagnosis of breast cancer. However, the frequency of aberrant methylation in white blood cells (WBC) as a potential biomarker of risk has not been extensively investigated. We hypothesized that aberrant promoter methylation of $B R C A 1, C D H 1$ and $R A R \beta$ would be detectable in WBC DNA of breast cancer patients and there would be a correlation between methylation in tumor tissue and blood DNA but with more frequent methylation in tissue DNA.

In the present study, we determined whether methylation in BRCA1, CDH1 and RAR $\beta$ in WBC DNA differed between cases and controls in the Long Island Breast Cancer Study Project (LIBCSP). Since tumor methylation for these genes was available for a large subset of the cases, we also determined the correlation between methylation status in tumor and WBC DNAs from cases.

\section{Materials and Methods}

\section{Study population and data collection}

We utilized the resources from the case-control component of the LIBCSP, a population-based investigation. Details of the study participants and design have been described previously [13-15]. In brief, eligible case participants included English speaking adult female residents of Nassau and Suffolk counties on Long Island, NY. Eligible case women were of all ages and races and newly diagnosed with in situ or invasive breast cancer between August 1, 1996, and July 31, 1997. Potentially eligible controls were frequency-matched to the expected age distribution of the cases by 5 -year age groups and identified through random digit dialing for women age $<65$ years and the Health Care Finance Administration rosters for women age $\geq 65$ years. Controls were defined as women who resided in the same Long Island counties as the cases, but who had no personal history of breast cancer.

The interviewer-administered structured casecontrol questionnaire was used to assess a number of personal, demographic and breast cancer-related characteristics. The questionnaire was completed by $82.1 \%$ of eligible cases $(n=1,508)$ and $62.8 \%$ of eligible controls $(n=1,556)$ and was administered within a few months of diagnosis. Among women who completed the questionnaire, $73.1 \%$ of cases $(n=1,102)$ and $73.3 \%$ of controls $(n=1,141)$ donated a blood sample. Of these, 1,021 cases and 1,036 controls with enough DNA for MethyLight analysis were included in the present study. The study protocol was approved by the Institutional Review Boards of the collaborating institutions.

\section{Sample collection and DNA preparation}

Blood samples were collected at the time of the case-control interview by trained field staff and DNA was isolated from blood specimens using the methods previously described [15]. DNA was available for 1,021 cases and 1,036 controls. Archived pathology blocks from $962(63.8 \%)$ women were successfully retrieved from the 33 hospitals in the Long Island study area. Isolation of tumor tissues from paraffin sections and tumor DNA were as previously described $[16,17]$.

\section{Methylation analysis}

DNAs first underwent bisulfite modification using the CpGnome DNA Modification Kit (Chemicon International, Purchase, NY) following the manufacturer's protocol. Sodium bisulfite-treated WBC DNA was analyzed by the MethyLight technique as described previously [18]. The primers and probes for BRCA1, CDH1, RAR $\beta$ and $\beta$-actin (ACTB) were previously described $[10.19,20]$. Specificity of the reactions for methylated DNA was confirmed separately using $\mathrm{CpGenome} \mathrm{T}^{\mathrm{TM}}$ Universal methylated and unmethylated DNAs (Chemicon, MA, USA). Relative quantification was determined based on the threshold cycles of the gene of interest and of the internal reference gene. The percentage of methylation at a specific locus was calculated by the $2^{-\Delta \Delta \mathrm{CT}}$ method [21]. For the $2^{-\Delta \Delta \mathrm{CT}}$ method to be valid, the amplification efficiencies of the test genes and reference gene, ACTB must be approximately equal. This was examined using real-time PCR and Taqman detection of serial dilutions of DNA with a 100-fold range and gene-specific primers of each gene and $A C T B$. The $\Delta C_{T}\left(C_{T, \text { Target gene }}-C_{T, \text { Reference }}\right)$ was calculated for each DNA dilution and a plot of the log DNA dilution vs $\Delta \mathrm{C}_{\mathrm{T}}$ was made. All amplification efficiencies were similar (data not shown). All samples were assayed in duplicate and the MethyLight assay was further validated by using mixtures of fully methylated and unmethylated DNA to give $0,0.1,0.5,1,5,10,25,50$ or $100 \%$ methylation.

Methylation data obtained from tumor tissue DNAs have been described in prior publications $[16,17]$. Among women who donated blood, tumor tissue data were available for 569,515 and 515 cases for $B R C A 1, C D H 1$ and $R A R \beta$, respectively. BRCA1 methylation in tumor tissue was determined by methylation-specific PCR (MSP) as described previously [16]. The CpG sites of BRCA1 covered in MSP were overlapped with those measured with the MethyLight assay. The MethyLight assay was used for determining the methylation status of $C D H 1$ and $R A R \beta$ in tumor tissue as described previously [17]. 


\section{Statistical Analysis}

Statistical analysis was performed using the SAS 9.1 (Cary, NC). The $\chi 2$ test was used to examine differences in the distributions of variables between cases and controls with methylation data. Among those with WBC methylation data, there were no significant case-control differences in the distributions of menopausal status, but cases were more likely to report a family history of breast cancer than controls $(18.8 \%$ vs. $14.2 \%$; $P=0.006)$. Cases with tumor data on gene methylation did not differ in age or family history from those with WBC methylation data. Cases with BRCA1 methylation data were somewhat less frequently postmenopausal (62\%) than those with data on $C D H 1$ and $R A R \beta(66 \%)$.

Odds ratios (ORs) and corresponding 95\% confidence intervals (CIs) for the association between methylation status and breast cancer risk were estimated by unconditional logistic regression [22]. We explored several constructions for the methylation exposure variable including binary models, where methylation status by MethyLight was categorized as positive if values were $\geq 1 \%, \geq 0.5 \%$, and $\geq 0.1 \%$, respectively; a 3-level categorical model (unmethylated, $<1 \%$ methylated, and $\geq 1 \%$ methylated); as well as continuous modeling. Potential confounders of the methylation-breast cancer association were identified though the literature and included: first degree family history of breast cancer (yes/no); body mass index $(\mathrm{BMI}=$ weight in kilograms/height in meters squared) (categorical); physical activity (categorical); smoking history (ever/never); and alcohol history (ever/never). Covariates were included in the final model if their inclusion changed the exposure estimate by $>10 \%$ [23]. Only family history of breast cancer, BMI and physical activity altered the estimate by greater than $10 \%$. Final models were therefore adjusted for each of these variables as well as 5-year age group.

The kappa coefficient (and corresponding 95\% confidence intervals) was used to compare the proportion of subjects defined as hypermethylated in WBC vs. tumor tissue for each of the three breast cancer-related tumor suppressor genes, BRCA1, CDH1 and RAR $\beta$ [24].

\section{Results}

$B R C A 1, C D H 1$ and $R A R \beta$ were rarely methylated in WBC DNA from either cases or controls with only 6, 2 and 1 subjects for BRCA1,CDH1 and RAR $\beta$, respectively, when values of $>10 \%$ were considered as positive. Using $\geq 1 \%$ as the cutoff for positive methylation, methylation frequencies of BRCA1, CDH1 and $R A R \beta$ were $1.8 \%, 2.0 \%$ and $1.5 \%$, in cases and $1.3 \%$, $1.1 \%$ and $1.5 \%$ in controls, respectively. In contrast, when we used the $\geq 0.1 \%$ cutoff to define positive methylation status we observed more frequent hypermethylation in WBC DNA for both cases and controls (Table 1).

We found little evidence of association between any of the genes and breast cancer risk modeling methylation as a continuous variable (Table 1). Given the low proportion of women classified as positive using $\geq 1 \%$ or $\geq 0.5 \%$ methylated definitions, our binary exposure models revealed non-significant associations between hypermethylation of $B R C A 1, C D H 1$ and $R A R \beta$ and breast cancer risk. We did, however, find evidence of association upon classifying women with $\geq 0.1 \%$ methylation as positive. Hypermethylation of BRCA1 (OR: 1.31; 95\% CI: 0.98-1.75) was associated with increased risk of breast cancer, while hypermethylation of CDH1 (OR: 0.65; 95\% CI: 0.54-0.79) and RAR $\beta$ (OR: 0.67; 95\% CI: 0.55-0.81) was associated with reduced risk (Table 1). Our three-level categorical model revealed similar modest inverse associations with breast cancer risk for $R A R \beta$ (Table 1 ).

Table 1. Hypermethylation in white blood cell DNA in breast cancer cases and controls, Long Island Breast Cancer Study Project, 1996-1997.

\begin{tabular}{|c|c|c|c|c|c|c|c|c|c|}
\hline & \multicolumn{3}{|c|}{$\underline{B R C A 1}$} & \multicolumn{3}{|c|}{$\underline{\mathrm{CDH1}}$} & \multicolumn{3}{|c|}{$\underline{R A R \boldsymbol{\beta}}$} \\
\hline & Case/Control & $\mathrm{OR}^{\mathrm{a}}$ & $95 \% \mathrm{CI}$ & Case/Control & $\mathrm{OR}^{\mathrm{a}}$ & $95 \% \mathrm{CI}$ & Case/Control & $\mathrm{OR}^{\mathrm{a}}$ & $95 \% \mathrm{CI}$ \\
\hline Continuous Model & $1021 / 1036$ & 1.03 & $(0.98,1.09)$ & $1021 / 1036$ & 1.04 & $(0.86,1.26)$ & $1021 / 1036$ & 0.89 & $(0.68,1.17)$ \\
\hline \multicolumn{10}{|l|}{ Binary Models } \\
\hline Un-Methylated & $1003 / 1023$ & 1 & Reference & $1001 / 1025$ & 1 & Reference & $1006 / 1020$ & 1 & Reference \\
\hline$\geq 1 \%$ Methylated & $18 / 13$ & 1.22 & $(0.57,2.60)$ & $20 / 11$ & 1.73 & $(0.76,3.94)$ & $15 / 16$ & 0.62 & $(0.29,1.34)$ \\
\hline Un-Methylated & $985 / 1004$ & 1 & Reference & $959 / 969$ & 1 & Reference & 976/995 & 1 & Reference \\
\hline$\geq 0.5 \%$ Methylated & $36 / 32$ & 1.07 & $(0.64,1.78)$ & $62 / 67$ & 0.73 & $(0.49,1.07)$ & $45 / 41$ & 0.81 & $(0.51,1.30)$ \\
\hline Un-Methylated & $894 / 932$ & 1 & Reference & $426 / 352$ & 1 & Reference & $688 / 632$ & 1 & Reference \\
\hline$\geq 0.1 \%$ Methylated & $127 / 104$ & 1.31 & $(0.98,1.75)$ & $595 / 684$ & 0.65 & $(0.54,0.79)$ & $333 / 404$ & 0.67 & $(0.55,0.81)$ \\
\hline \multicolumn{10}{|l|}{ Categorical Model } \\
\hline Un-Methylated & $894 / 932$ & 1 & Reference & $426 / 352$ & 1 & Reference & $688 / 632$ & 1 & Reference \\
\hline $0.1-<1 \%$ Methylation & $109 / 91$ & 1.32 & $(0.97,1.80)$ & $575 / 673$ & 0.65 & $(0.53,0.78)$ & $318 / 388$ & 0.64 & $(0.55,0.82)$ \\
\hline$\geq 1 \%$ Methylation & $18 / 13$ & 1.25 & $(0.58,2.67)$ & $20 / 11$ & 1.29 & $(0.56,2.97)$ & $15 / 16$ & 0.53 & $(0.24,1.14)$ \\
\hline
\end{tabular}

a Odds ratio: adjusted for age, family history, body mass index and physical activity 
Table 2. Promoter hypermethylation in breast tumors, among cases, and paired white blood cell DNA using $>0.1 \%$ methylated as classification for +/- in blood. Long Island Breast Cancer Study Project, 1996-1997.

\begin{tabular}{|c|c|c|c|}
\hline & \multicolumn{3}{|c|}{ Number of cases (\%) } \\
\hline & BRCA1 & CDH1 & $R A R \beta$ \\
\hline \multicolumn{4}{|l|}{ Methylation Statusa } \\
\hline Tumor, UM $\mathrm{UM}^{\mathrm{b}} / \mathrm{WBC} \mathrm{c}, \mathrm{UM}$ & $202(35.5)$ & $166(32.2)$ & $184(35.7)$ \\
\hline Tumor, UM / WBC, $\mathrm{M}^{\mathrm{d}}$ & $29(5.1)$ & $230(44.7)$ & $102(19.8)$ \\
\hline Tumor, M / WBC, UM & $288(50.6)$ & $41(8.0)$ & $148(28.8)$ \\
\hline Tumor, M / WBC M & $50(8.8)$ & $78(15.1)$ & $81(15.7)$ \\
\hline Kappa Statistic $(95 \%$ CIe) & $0.019(-0.030,0.068)$ & $0.048(-0.016,0.112)$ & $-0.003(-0.088,0.082)$ \\
\hline
\end{tabular}

a Promoter methylation in tumor tissue was classified as $+/$ - for BRCA1 and $\geq 4 \%$ for CDH1 and RAR6

b Unmethylated

c White Blood Cell

d Methylated

e Confidence Interval

We previously analyzed promoter hypermethylation in tumor tissues for BRCA1, CDH1 and RAR $\beta$ $[16,17]$. Tumor tissues were more frequently hypermethylated (defined as $>4 \%$ methylation) than blood DNA for all genes tested (59.3\% for BRCA1 [16], 23.3\% for $C D H 1$ [17] and $44.5 \%$ for $R A R \beta$ [17]). Methylation of all three genes was discordant between tumor tissue and paired WBC DNA using $\geq 0.1 \%$ methylated as the cutoff for positive methylation status in WBC (Table 2).

\section{Discussion}

In a large population-based, case-control study of women with breast cancer, we found that hypermethylation of BRCA1 may be associated with breast cancer risk when using very low levels of methylation (i.e. $\geq 0.1 \%$ ) as the cutoff for comparison. Although two prior studies reported a significantly higher frequency of WBC BRCA1 methylation in breast cancer cases [25, 26], two others found no difference [27, 28]. In contrast, WBC BRCA1 methylation at levels as high as $17 \%$ has been consistently observed in $5-43 \%$ of women with BRCA1 mutation-associated pathology but without germline BRCA1 mutations, suggesting rare constitutional methylation [25, 29]. Two studies have also suggested that methylation of specific regions in ATM may be associated with increased breast cancer risk [30, 31]. An analysis of 25 genes reported that methylation of five genes (ZNF217, NEUROD1, SFRP1, TITF1 and NUP155) in WBC was associated with breast cancer risk [32]. The original 25 genes were selected because they are estrogen receptor-a targets, known to be differently methylated depending on hormone receptor status, known to contain stem cell polycomb group targets or known to be methylated in breast cancer.

Here we used the MethyLight assay to determine WBC methylation for three candidate genes frequently methylated in breast cancer. This method allows rapid analysis of large numbers of samples and provides continuous data on \% methylation calculat- ed versus a "fully methylated" standard sample, which in this study was purchased from a commercial source. Previously, we have analyzed methylation for this type of material and found methylation levels ranging from $85-95 \%$. This suggests that levels of methylation may not be accurate although relative methylation levels should be valid. In addition, there is no generally accepted cutoff for use in determining hypermethylation in WBC DNA. In our prior study of tumor tissue, we used $4 \%$ methylation as the cutoff since this value had been used previously [33]. However, one recent study used $0.1 \%$ methylation as the cutoff with cancer samples [34]. Thus, for WBC methylation we tested different cutoffs for the definition of hypermethylation including $\geq 1 \%, 0.5 \%$ or $0.1 \%$. While the number of subjects with hypermethylation increased as the cutoff was lowered, only for $B R C A 1$ was there a suggestion of a positive association between hypermethylation and breast cancer risk. The inverse relationships between methylation of $C D H 1$ and $R A R \beta$ and breast cancer risk are difficult to explain. Many more controls are considered positive for methylation when using the criteria $\geq 0.1 \%$ in CDH1 $(\mathrm{n}=684)$ and $R A R \beta(\mathrm{n}=404)$ than for BRCA1 $(n=104)$ and how this impacts results is unclear. The OR for CDH1 became inverted as the cutoff was lowered suggesting the data are unstable. In addition, the biological relevance of these very low levels of methylation is also unclear suggesting the results should be interpreted with caution.

Our results showed a discordance of hypermethylation of the genes tested between WBC and tumor tissue, similar to results observed previously for BRCA1 [35]. This finding suggests that a direct link between WBC BRCA1 methylation and development of breast cancer is still questionable.

One of the strengths of our study is the large sample size from a population-based case-control study (1,021 cases and 1,036 controls). In addition, the MethyLight assay we used is known to be sufficiently sensitive to detect methylated DNA present at low 
levels. However, despite these strengths, analyses were based on small numbers of women with hypermethylation because WBC DNA was rarely hypermethylated. Furthermore, the relatively modest number of tumor suppressor genes investigated precluded further analyses of the possible relationship between methylation levels and breast cancer risk. Thus, further studies with additional genes are needed to establish the usefulness of WBC DNA methylation as a marker of risk.

In conclusion, we examined methylation levels in tumor and WBC DNA from in situ or invasive ductal breast cancer patients and in WBC DNA from population-based controls to identify epigenetic markers of breast cancer risk. Obtained results suggest that hypermethylation of these three genes in WBC DNA may be associated with breast cancer risk, but additional studies on the biological significance of low-level methylation is needed to fully understand the observed results.

\section{Acknowledgments}

Research reported in this publication was supported by the following institutes in the National Institutes of Health: National Institute of General Medical Sciences P30GM103338; National Cancer Institute CA109753，CA/ES66572，CA66572，CA013696; National Institutes of Environmental Health and Sciences ES009089, and ES10126. The content is solely the responsibility of the authors and does not necessarily represent the official views of the National Institutes of Health. Additional funding support came from the Department of Defense BC031746, W81XWH-06-1-0298, and BC093608.

\section{Conflicts of Interest}

No potential conflicts of interests were disclosed.

\section{References}

1. Jones PA, Baylin SB. The fundamental role of epigenetic events in cancer. Nat Rev Genet. 2002; 3(6): 415-28.

2. Lian ZQ Wang $\mathrm{Q}$ Li WP, Zhang AQ, Wu L Screening of sionificantly hypermethylated genes in breast cancer using microarray-based methylated-CpG island recovery assay and identification of their expression levels. Int J Oncol. 2012; 41(2): 629-38.

3. Catteau A, Harris WH, Xu CF, Solomon E. Methylation of the BRCA1 promoter region in sporadic breast and ovarian cancer: correlation with disease characteristics. Oncogene 1999;18: 1957-65.

4. Nass SJ, Herman JG, Gabrielson E, Iversen PW, Parl FF, Davidson NE et al. Aberrant methylation of the estrogen receptor and E-cadherin 5' CpG islands increases with malignant progression in human breast cancer. Cancer Res. 2000;60:4346-8.

5. Sirchia SM, Ren M, Pili R, Sironi E, Somenzi G, Ghidoni R, et al. Endogenous reactivation of the RAR $\{$ beta $\} 2$ tumor suppressor gene epigenetically silenced in breast cancer. Cancer Res. 2002;62:2455-61.

6. Tserga A, Michalopoulos NV, Levidou G, Korkolopoulou P, Zografos G, Patsouris E, et al. Association of aberrant DNA methylation with clinicopathological features in breast cancer. Oncol Rep. 2012;27(5):1630-8.

7. Swift-Scanlan T, Vang R, Blackford A, Fackler MJ, Sukumar S. Methylated genes in breast cancer: associations with clinical and histopathological features in a familial breast cancer cohort. Cancer Biol Ther. 2011; 11(10): 853-65.
8. Barekati Z, Radpour R, Lu Q, Bitzer J, Zheng H, Toniolo P, et al. Methylation signature of lymph node metastases in breast cancer patients. BMC Cancer 2012; 12(1): 244 .

9. Mirza S, Sharma G, Parshad R, Srivastava A, Gupta SD, Ralhan R. Clinical significance of promoter hypermethylation of ER $\beta$ and RAR $\beta 2$ in tumor and serum DNA in Indian breast cancer patients. Ann Surg Oncol. 2012; 19(9): 3107-15.

10. Müller HM, Widschwendter A, Fiegl H, Ivarsson L, Goebel G, Perkmann E, et al. DNA methylation in serum of breast cancer patients: an independent prognostic marker. Cancer Res. 2003; 63: 7641-5.

11. Müller HM, Ivarsson L, Schröcksnadel H, Fiegl H, Widschwendter A, Goebel $\mathrm{G}$, et al. DNA methylation changes in sera of women in early pregnancy are similar to those in advanced breast cancer patients. Clin Chem. 2004; 50: 1065-8.

12. Silva JM, Dominguez G, Garcia JM, Gonzalez R, Villanueva MJ, Navarro F, et al. Presence of tumor DNA in plasma of breast cancer patients: clinicopathological correlations. Cancer Res. 1999; 59: 3251-6.

13. Gammon MD, Neugut AI, Santella RM, Teitelbaum SL, Britton JA, Terry MB, et al. The Long Island Breast Cancer Study Project: description of a multi-institutional collaboration to identify environmental risk factors for breast cancer. Breast Cancer Res Treat. 2002; 74: 235-54.

14. Cleveland RJ, Eng SM, Abrahamson PE, Britton JA, Teitelbaum SL, Neugut AI, et al. Weight gain prior to diagnosis and survival from breast cancer. Cancer Epidemiol Biomarkers Prev. 2007; 16: 1803-11.

15. Gammon MD, Santella RM, Neugut AI, Eng SM, Teitelbaum SL, Paykin A, et al. Environmental toxins and breast cancer on long island. I. polycyclic aromatic hydrocarbon DNA adducts. Cancer Epidemiol Biomarkers Prev. 2002; 11(8): 677-85.

16. Xu X, Gammon MD, Zhang Y, Bestor TH, Zeisel SH, Wetmur JG, et al. BRCA1 promoter methylation is associated with increased mortality among women with breast cancer. Breast Cancer Res Treat. 2009; 115: 397-404.

17. Cho YH, Shen J, Gammon MD, Zhang YJ, Wang Q, Gonzalez K, et al. Prognostic significance of gene-specific promoter hypermethylation in breast cancer patients. Breast Cancer Res Treat. 2012; 131(1): 197-205.

18. Eads CA, Lord RV, Wickramasinghe K, Long TI, Kurumboor SK, Bernstein L, et al. Epigenetic patterns in the progression of esophageal adenocarcinoma. Cancer Res. 2001; 61: 3410-8.

19. Widschwendter $M$, Siegmund KD, Müller HM, Fiegl $H$, Marth $C$, Müller-Holzner E, et al. Association of breast cancer DNA methylation profiles with hormone receptor status and response to Tamoxifen. Cancer Res. 2004; 64: 3807-13.

20. Fackler MJ, McVeigh M, Mehrotra J, Blum MA, Lange J, Lapides A, et al. Quantitative multiplex methylation-specific PCR assay for the detection of promoter hypermethylation in multiple genes in breast cancer. Cancer Res. 2004; 64: 4442-52.

21. Livak KJ, Schmittgen TD. Analysis of relative gene expression data using real-time quantitative PCR and the 2(-Delta Delta C(T)) Method. Methods 2001; 25: 402-8.

22. Kleinbaum DG, Klein M. Logistic regression; a self-learning text; 2nd ed. New York: Springer; 2002: p513.

23. Greenland S. Modeling and variable selection in epidemiologic analysis. Am J Public Health 1989; 79(3): 340-9.

24. Fleiss JL. Statistical Methods for Rates and Proportions. Second edition. John Wiley \& Sons, New York; 1981.

25. Wong EM, Southey MC, Fox SB, Brown MA, Dowty JG, Jenkins MA, et al. Constitutional methylation of the BRCA1 promoter is specifically associated with BRCA1 mutation-associated pathology in early-onset breast cancer. Cancer Prev Res (Phila). 2011; 4(1): 23-33.

26. Iwamoto T, Yamamoto N, Taguchi T, Tamaki Y, Noguchi S. BRCA1 promoter methylation in peripheral blood cells is associated with increased risk of breast cancer with BRCA1 promoter methylation. Breast Cancer Res Treat. 2011; 129(1): 69-77.

27. Bosviel R, Garcia S, Lavediaux G, Michard E, Dravers M, Kwiatkowski F, et al. BRCA1 promoter methylation in peripheral blood DNA was identified in sporadic breast cancer and controls. Cancer Epidemiol. 2012; 36(3): e177-182.

28. Wojdacz TK, Thestrup BB, Cold S, Overgaard J, Hansen LL. No difference in the frequency of locus-specific methylation in the peripheral blood DNA of women diagnosed with breast cancer and age-matched controls. Future Oncol. 2011; 7(12): 1451-5.

29. Snell C, Krypuy M, Wong EM, Loughrey MB, Dobrovic A. BRCA1 promoter methylation in peripheral blood DNA of mutation negative familial breast cancer patients with a BRCA1 tumour phenotype. Breast Cancer Res. 2008; 10: R12.

30. Flanagan JM, Munoz-Alegre M, Henderson S, Tang T, Sun P, Johnson N, et al. Gene-body hypermethylation of ATM in peripheral blood DNA of bilateral breast cancer patients. Hum Mol Genet. 2009; 18: 1332-42.

31. Brennan K, Garcia-Closas M, Orr N, Fletcher O, Jones M, Ashworth A, et al. Intragenic ATM methylation in peripheral blood DNA as a biomarker of breast cancer risk. Cancer Res. 2012; 72(9): 2304-13.

32. Widschwendter M, Apostolidou S, Raum E, Rothenbacher D, Fiegl H, Menon $\mathrm{U}$, et al. Epigenotyping in peripheral blood cell DNA and breast cancer risk: a proof of principle study. PLoS One 2008; 3(7): e2656.

33. Eads CA, Lord RV, Kurumboor SK, Wickramasinghe K, Skinner ML, Long TI, et al. Fields of aberrant CpG island hypermethylation in Barrett's esophagus and associated adenocarcinoma. Cancer Res. 2000; 60(18): 5021-6. 
34. Bu D, Lewis CM, Sarode V, Chen M, Ma X, Lazorwitz AM, et al., Identification of Breast cancer DNA methylation Markers optimized for fine-needle aspiration samples. Cancer Epidemiol Biomarkers Prev. 2013; 22(12): 2212-21.

35. Wojdacz TK, Thestrup BB, Overgaard J, Hansen LL. Methylation of cancer related genes in tumor and peripheral blood DNA from the same breast cancer patient as two independent events. Diagn Pathol. 2011; 6: 116. 